\title{
Comparison of Shade Match Compatibility between Vitapan Classical and 3D Master Shade Guide Systems by Dental Students in Tabriz Faculty of Dentistry
}

Ramin Negahdari ${ }^{1}$, Alireza Pournasrollah ${ }^{1}$, Mahdi Rahbar ${ }^{2}$, Sepideh Bohlouli ${ }^{3}$, Seyyed Mahdi Vahid Pakdel $^{4^{*}}$

1. Assistant Professor, Department of Prosthodontics, Faculty of Dentistry, Tabriz University of Medical Science,

Tabriz, Iran

2. Post-graduate Student, Department of Operative Dentistry, Faculty of Dentistry, Tabriz University of Medical Science, Tabriz, Iran

3. Assistant Professor, Department of Oral medicine, Faculty of Dentistry, Tabriz University of Medical Science, Tabriz, Iran

4. Post-graduate Student, Department of Prosthodontics, Faculty of Dentistry, Tabriz University of Medical Science, Tabriz, Iran

\begin{abstract}
Background and Aims: Dentists perform color-match process during indirect and direct restorations. Color research has shown that shade guides do not always match the color of natural teeth. Moreover, visual evaluation of dental colors has been found to be inconsistent and unreliable. In fact, it has always been important when using different shade guides. Our purpose in this study was to compare shade selection using two shade guide systems of Vitapan Classical and 3D Master by dental students of Tabriz University of Medical Sciences. Materials and methods: In this analytical, cross-sectional descriptive study, 20 male and 20 female senior dental students with a little clinical experience in working with shade guides were selected. Each student used two shade guides (Vitapan Classical and 3D Master) separately for shade matching. Shade selection was randomly repeated one week later by the same protocol. T-test was used to compare repeatability of color matching $(\alpha=0.05)$. Comparison of the repeatability percentage was done with t-test. Results: Comparison of repeatability percentages of shade matching irrespective of gender showed that percentage of repeatability of shade match in 3D Master system was significantly high $(P=0.00)$. In addition comparison of repeatability means of shade match with different shade guide systems on the basis of gender showed no significant differences $(P=0.68)$. Conclusion: In general, the repeatability percentages of shade matching in 3D Master system was high and shade matching in females with this system was not different than males.
\end{abstract}

Key words: Color vision; indirect restorations; dental students

\section{Corresponding author:}

Seyyed Mahdi Vahid Pakdel

Prosthodontics Department, Dental School, Tabriz University of Medical Sciences, Tabriz, Iran Email: og.smvp@gmail.com Phone number: +989144087289 Cell phone: +984133355967

Receive date: 2015-10-10| Accept date: 2015-10-28| Publish date: 2015-12-01

DOI: 10.7575/aiac.abcmed.16.04.01.02 


\section{Introduction}

Given the increasing number of patients demanding esthetic dental treatments and an increase in the mean age of the population, leading to an increase in the number of patients needing prosthetic treatments, it is very important to have knowledge about variations in the colors of natural teeth and the efficacy of shade guide systems in meeting the esthetic needs of patients (1).

Color identification is very difficult, which requires not only knowledge but also it is considered an art (2). Matching the color of restorations with that of teeth is one of the most difficult issues in restorative dentistry. 3 In some restorative or prosthetic treatments all the artistic factors are observed but the treatment ends in failure due to errors ion color selection and matching steps. A mismatch between the color of the restored tooth and that of the other teeth might result in extra costs to replace the restoration or the prosthetic appliance at the expense of the dentist, patient dissatisfaction and unfavorable consequences for the reputation of the dentist (4).

Wasson et al (5) reported that color selection is an important and vital procedure in restorative dentistry but dentists are never tested on color selection. Wasson carried out a study on 150 dentists (75 males and 75 females) to evaluate color selection for porcelains. The results showed that $9.3 \%$ of male dentists had problems with color selection, with none of the female dentists having such a problem, indicating potential weaknesses in some dentists in this respect. It was suggested that the easiest technique to solve such a problem is to use mechanical tools or to adopt a restorative approach.

Gear et al (6) reported that the difference between the shade guides and the natural colors of teeth should be minimized to decrease such problems. To this end, Geary carried out a study to determine whether there were differences between individuals who used the same shade guide or not. A total of 70 dentists were included in the study and considering the existing match between the shades suggested by the manufacturers and the shades selected by the dentists, it was concluded that dentists have different concepts about colors.

Cartsen (7) reported that dentists should be familiar with the intrinsic and extrinsic factors affecting human vision for correct shade selection. The study showed that objects only reflect the light that has been projected on them and the eye can distinguish the hue, the value and the chroma of the reflected light. Therefore, light with correct intensity is a prerequisite for correct color selection.

A study showed that the sunlight is the most appropriate light for shade selection; however, it is not possible to provide adequate sunlight in all the occasions. Therefore, suitable artificial light should be used. In addition, it was reported that dentists who had incorrect shade selection were unable to distinguish colors properly. In fact, all the men suffer from color vision confusion to some extent, which might be permanent or temporary (8).

Burak et al (9) carried out a study with the use of Vitapan shade guide. They asked 13 male and 22 female restorative dental students to select shades with the use of this system. Based on the results, no significant differences were observed in the accuracy and repeatability between students with the use of this shade guide.

Another study on the clinical efficacy of Vitapan Classical and 3D Master shade guides showed that the crowns undergoing shade selection with the 3D Master shade guide could be cemented without the need for any shade 
modification; however, $17 \%$ of restorations that had undergone shade selection with the Vitapan Classical shade guide required some shade modification (10). In addition, another study showed clinical differences between 3D Master and Vitapan Classical shade guides in evaluations carried out on general dental practitioners and prosthodontists with at least 14 years of experience under standard conditions; repeatability of shade selection in general dental practitioner with the use of 3D Master was significantly higher than that with the Vitapan Classical shade guide. However, prosthodontists did not exhibit such a difference (11).

Ghahramani et al (12) carried out a study to evaluate the repeatability of color selection with the use of Vitapan Classical and 3DMaster shade guides by 10 male and 10 female 6thyear dental students and reported no significant differences in the repeatability between these two systems.

Sometimes two objects (e.g. tooth shade guides) exhibit the same shade under one light source such as natural light, but they exhibit differences under a different light source, e.g. artificial light. This phenomenon is referred to as metamerism and should always be taken into account (13).

Studies have shown that clinicians with less experience exhibit greater success in correct color selection with the use of shade guides that have been organized in a systematic manner, such as the 3D Master shade guide (14). In addition, 3D Master exhibits the least visual errors compared to Vitapan Classical (11).

Egger (14) showed that natural teeth can be classified into three color groups using spectrophotometric analyses: yellow, orange and red. In addition, apart from differences in chroma, there are differences in value, too. Therefore, in determining tooth color, the chroma and value should also be taken into account in addition to hue. The color match between the teeth and restorations is one of the most important factors in achieving esthetic results. The color match of a shade selection system is the strong point of that system, reflecting the standardization of matching of the color samples in that system. In previous studies human tooth samples have been used to determine the accuracy of color selection by dental students or dentists. However, no studies are available in which the color determination accuracy of the shade guides themselves have been evaluated. Therefore, the present study was undertaken to make the students familiar with the practical aspects of color science and also determine which shade guide systems exhibit a higher degree of standardization and coordination. In this study, the Vita Classical and 3D Master shade guide systems were used and compared by dental students in Tabriz Faculty of Dentistry.

\section{Materials and Methods}

The subjects in the present cross-sectional, analytical descriptive study consisted of dental students in Tabriz Faculty of Dentistry. The sample size was determined at 40 students based on previous studies (12) and by considering $\alpha=0.05$, a test power of $80 \%$ and $80 \%$ of correct selection of color. Twenty male and 20 female subjects were included in this study in a random manner.

The inclusion criterion was the last-year (12th semester) dental students. The exclusion criteria consisted of age under 20 or over 39, unwillingness to take part in the study and affliction with color blindness as determined by Ishihara test. Two shade selection systems, Vitapan Classical and Vita 3D Master (Vita Zahnfabrik, Germany), were used for the purpose of the study. Seven shade/color samples were randomly selected from each system, which included A1, A4, B2, B3, C2, C4 
and D3 from the Vitapan Classical system and $1 \mathrm{M} 2,4 \mathrm{M} 3,4 \mathrm{~L} 1.5,2 \mathrm{M} 2,3 \mathrm{M} 1,4 \mathrm{R} 1.5$ and 2R1.5 from the 3D Master system. Then the shades/colors of both systems were placed, randomly and separately, on the periphery of a rotating plate (Figure 1) and the shade codes were covered with a tape and only each shade's tab was left visible.

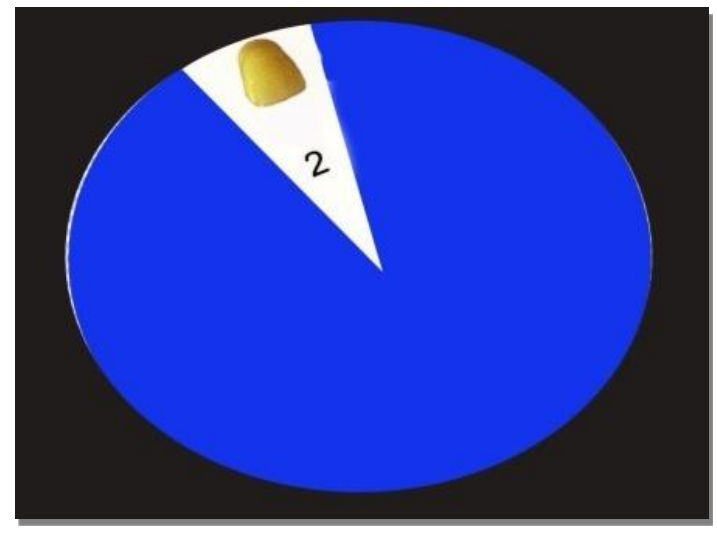

Figure 1: The rotating plate specially prepared for the purpose of this study

The procedural steps were carried out in a room measuring $3 \times 4 \mathrm{~m}$, specially prepared for shade selection with grey floor, ceiling and walls, with controlled lighting conditions, i.e. standard fluorescent light (day light, 65000k). Each observer (student) was asked to determine the shades of the Vitapan Classical samples on the rotating plate with the use of the 3D Master shade guide, and vice versa, from 10 a.m. to 2 p.m. while sitting with his/her back toward the window. The color determination procedures were repeated after a week due to the subjective mature of the color determination procedure. However, the second time the order of the shade samples was changed on the rotating plate to prevent the students from using their memory to determine shades. It should be pointed out that the subjects were instructed in how to use the two shade selection systems one week before the study was actually initiated.
In addition, during the intervals between the shade determination procedures the students were asked to look at a blue plate to prevent eye tiredness ( 8 ). The shades determined by the students for each test shade were separately recorded for each system in the relevant questionnaires.

After the tests were completed, the repeatability percentages of shade determination for each system were calculated for each group using the following formula:

Repeatability percentage for each group $=\frac{\text { The total correct shade selection }}{14} \times 100$

Comparison of the repeatability percentage was done with t-test.

\section{Results}

The means repeatability percentages of shade selection by male subjects were $47.1 \%$ and $56.9 \%$ with the Vitapan Classical and 3D Master systems, respectively. These means in the female subjects were $54.7 \%$ and $69.1 \%$, respectively. The overall percentages of correct shade selection were $46.4 \%$ and $63 \%$ with the use of Vitapan Classical and 3D Master systems, respectively. These mean percentages show that the repeatability percentages of color matching were better in the 3D Master better than the Vitapan Classical system $(P<0.05)$. In general, statistical analyses showed significant differences between the Vitapan Classical and 3D Master shade guides, with the latter exhibiting higher repeatability rate compared to the former.

Comparison of the accuracy of selections made by males and females in each of the shade selection systems showed that in none of these systems there were significant differences between males and females.

\section{Discussion}

There is an increase in the community members' attention to and interest in having teeth with esthetic appearance with an 
increase in the cultural level and hygiene status The science of colors is considered an important tool in achieving this aim and obtaining the best esthetic results from treatments. As a result, color is considered an important subject in the dental field (11). However, the concept of color is difficult in different subjects, not only requiring knowledge, but also considered an art (2).

Considering what was discussed above and based on the results of previous studies, it is obvious that determining and understanding color is under the influence of various factors and such a concept is not the same between clinicians, with the shade selection system playing an important role in selecting a correct shade/color (11). Although the shade guide systems do not completely reflect the colors/shades of natural teeth, they are still considered the chief tools for the evaluation and selection of color in clinical dentistry (11).

One of the most commonly used shade guide systems used in Iran is the Vitapan Classical system. Considering the limitations of this shade guide, the manufacturer has recently introduced a new shade guide with higher efficacy, referred to as Vitapan 3D Master, which has been used and evaluated in recent research (16).

In the present study, the Vitapan Classical and Vita 3D Master shade guide systems were used and shade selection was carried out in a $3 \times 4$ room, with grey walls and ceiling under controlled lighting conditions (standard fluorescent light, day light, 65000k).

The results of the present study showed significant differences between these two shade guide systems, irrespective of the subjects' genders, with the 3D Master system exhibiting higher repeatability compared to the Vitapan Classical system $(P=0.00)$, consistent with the results of a study by Hamad et al (11) of the community along with oral hygiene (1). and contrary to the results of a study by Ghahramanlou et al (12).

Given the advantages of the 3D Master shade guide system, including ease and the step-wise nature of procedures and separation of color components in different stages of color/shade selection, compared to the Vitapan Classical system, it appears it is easy to use this system $(11,17)$. Therefore, clinicians with less experience and dental students can select colors with more accuracy and can avoid shade correction at the end of the procedures by using a system that guides them in a systematic and adjusted manner during shade selection procedures $(11,17,18)$.

Bayindir et al (18) evaluated the errors of shade guide systems and concluded that 3D Master shade guide system has lower visual errors compared to Vitapan Classical system (18).

Hassel et al (17) compared the clinical efficacy of Vitapam Classical and 3D Master and reported that crowns undergoing color selection with 3D Master could be cemented without any shade modification; however, 17\% of restorations undergoing color selection with Vitapan Classical required shade modification.

Paul et al (19) compared the crowns undergoing shade selection through spectrophotometric and visual techniques with Vitapan Classical shade guide and concluded that commercial Vitapan Classical shade guide does not reflect the whole range of the color of natural teeth, consistent with the results of a study by Wee et al (20).

In the present study, statistical analyses did not reveal any statistically significant differences in the ability of male and female subjects in selecting the correct shade with the use of both shade guides; however, males exhibited higher shade compatibility with the use of the Vitapan Classical shade guide 
$(P=0.688)$ and females exhibited a higher percentage of repeatability with the use of the 3D Master system $(P=0.082)$.

Curd et al (21) carried out a study on shade matching by dental students with the use of two different light sources and reported no significant differences in the ability to match shades between male and female students, consistent with the results of the present study.

In addition, since shade selection depends on many factors, including lighting conditions and the color of the environment, the eyes of the observer and mental and psychological factors, it has been suggested that dentists seek help from their assistants or use newer tools for shade matching, such as Vitapan 3D Master and spectrophotometric and colorimetric techniques for better and more accurate shade matching (22). Furthermore, it has been suggested that in future studies all the subjects be tested with the use of Munsell color sphere to achieve better shade match results (22).

Finally, it is suggested that lessons and courses be included in the syllabi of the general dentistry course in relation to colors and light to make dental students more knowledgeable in tooth shade matching.

\section{Conclusion}

Based on this study, it can be concluded that the repeatability percentages of tooth shade selection were significantly higher with the use of the 3D Master shade guide, with no difference in males and females color recognition.

\section{References}

1. Sturdevant CM, Roberson TM, Heymann HO, Sturdevant JR: The Art and Science of Operative Dentistry. 4th Ed. St. Louis: The C.V Mosby Co. 2001;Chap 15:593-604.

2. Paravina R, Hankovic D. Problems in standard shade matching and reproduction in dentistry. Scientif J Facta Universita 1997;4:12-16.

3. Fondriest J. Shade matching in restorative dentistry: The science and strategies. Int J Perio Resto Dent 2003;23:46779.

4. Sadr J: Light and Color in Dentistry. 1st Ed. Tehran, Jahade Daneshgahi Shahid Beheshti University 1985;Chap 4:9194.

5. Wasson W, Schuman N. Color Vision and Dentistry. Quint Int 1992;23:349-53.

6. Geary JL, Kinirons MJ. Use of a common shade guide to test the perception of differences in the shades and value by members of the dental team. Prim Dent Care 1991;6:107-110.

7. Carsten DL.(2003). Successful shade matching-what does it take? Compend Contin Educ Dent 2003;24:175$8,180,182$

8. Shillingburg TH, Hubo S, Witsett DL, Jacobbi R, Bracket SA. The Principles of Fixed Prostheses. 3rd Ed. Noure Danesh Publishing Co. Tehran 2003; Chap 23:429.

9. Burak Yılmaz, Bulem Yuzugullu, Duygu Çınar, Semih Berksun.(2011). Effects of shade tab arrangement on the repeatability and accuracy of shade selection. The Journal of Prosthetic Dentistry 2011;105(6):383-86.

10. Hassel AJ, Koke U, Schmitter M, Becka J, Rammeisberg P. Clinical effect of different shade guides system of the tooth of ceramic-veneer restoration. Int J Prosthet 2005;18(4):422-6.

11. Hamad IA. Intrarater Repeatability of shade selection with two shade guides. J Prosthet Dent 2003;89(1):50-8. 
12. Ghahramanloo A., Goharian R., Esmaeeli H., Shahalamy S.R. (2008).Evaluation of Shade Selection Repeatability with Vita-Classic \& 3DMaster by Two Groups of Male and Female Students of Mashhad Dental School. Journal of Mashhad Dental School 2008;32(3):213-20.

13. Moscardó A, Camps Alemany I. Aesthetic dentistry: Chromatic appreciation in the clinic and the laboratory. Med Oral Patol Oral Cir Bucal 2006;11:E363-8.

14. Egger B. Natural Color Concept: A Systematic Approach to Visual Shade Selection, Quintessence of Dental Technology (QDT) 2003;26:161.

15. Rosentiel SF, Land FM, Fujimoto. Contemporary Fixed Prosthodontics. 4th Ed. St. Louis: The C.V Mosby Co.2006; Chap 23:711,715.

16. Mahshid M, Sabouri A, Ashtaralnakhaei A, Sahabi M, Monzavi R, Khodami H. Evaluation of repeatability in observers in shade selection under two different high sources with two different shade guides. The Dental Journal of Shahid Beheshti University of Medical Sciences 2006;24(2):261-268.

17. Hassel AJ, Koke U, Schmitter M, Becka J, Rammeisberg P. Clinical effect of different shade guides system of the tooth of ceramic-veneer restoration. Int J Prosthet 2005;18(4):422-6.

18. Bayindir F, Kuo S, Johnston WM, Wee AG. Coverage error of the conceptually different shade guide systems to vital unrestored dentition. J Prosthet Dent 2007;98(3):175-85.

19. Paul SJ, Peter A, Rodoni L, Pietrobo N. Conventional Visual Vs Spectrophotometric Shade Taking For PFM Crowns. Int Perio Res Dent 2004;24(3):222-31.

20. Wee AG, Kang EY, Jere D, Beck FM. Clinical color match of porcelain visual shade-matching systems. J Esthet Restor Dent 2005;17(6):351-7.

21. Curd FM, Jasinevicius TR, Graves A, Cox V, Sadan A. Comparison of the shade matching ability of dental students using two light sources. J Prosthet Dent 2006;96(6):391-6.

22. Danesh Kazemi A, Besheshti M, Davari A, Khani Basiri R. Evaluation of color match of dental students in Yazd in 2004. The Dental Journal of Shahid Beheshti University of Medical Sciences 2008;26(1):40-46. 